\title{
REGENERATED SPENT BLEACHING EARTH FOR THE DECOLOURISATION AND BOD REDUCTION OF PALM OIL MILL EFFLUENT
}

\author{
RUSNANI ABD MAJID* and CHE RAHMAT CHE MAT*
}

\begin{abstract}
The aim of the present study is to evaluate the possibility of re-using the regenerated spent bleaching earth, subjected to acid and heat treatment, to decolourise and reduce the biological oxygen demand (BOD) of the final effluent discharged from palm oil mills. Different types of clays namely spent bleaching earth that has been regenerated using acid and heat treatment after de-oiling (RDSBE-AH), spent bleaching earth (SBE), de-oiled spent bleaching earth (DSBE) and new bleaching earth (NBE) were characterised for their surface area, pore volume and functional groups. RDSBE-AH was found to have the highest surface area and pore volume when compared to the other three types of clays with values of $122.3 \mathrm{~m}^{2} \mathrm{~g}^{-1}$ and $68 \mathrm{~cm}^{3} \mathrm{~g}^{-1}$, respectively. In terms of decolourisation, RDSBE-AH exhibited a higher efficiency than NBE. Higher BOD reduction efficiency was found for NBE as compared to RDSBE-AH. The adsorption kinetic models on colour and BOD for both RDSBE-AH and NBE were well described by the pseudo-second order equation with very good coefficient of determination $\left(R^{2}\right)$. The results demonstrated that the regenerated $S B E$, produced through the combined acid and heat treatments, had the potential to decolourise and reduce the BOD of the palm oil mill's final effluent discharge.
\end{abstract}

Keywords: regenerated spent bleaching earth, palm oil mill effluent, adsorption, decolourisation, biological oxygen demand (BOD).

Date received: 10 March 2017; Sent for revision: 11 March 2017; Received in final form: 11 August 2017; Accepted: 7 September 2017.

\section{INTRODUCTION}

The bleaching process in palm oil refineries helps improve the appearance, flavour, taste and stability of the final palm oil products. Bleaching earth is the common adsorbent used in the bleaching process. This is due to its relatively high adsorption performance for coloured materials and low purchasing cost (Bayrak, 2003). The bleaching process however generates a large amount of solid wastes commonly known as spent bleaching earth (SBE). The SBE normally contains $17 \%$ to $30 \%$

\footnotetext{
Malaysian Palm Oil Board,

6 Persiaran Institusi, Bandar Baru Bangi,

43000 Kajang, Selangor, Malaysia.

E-mail: rusnani@mpob.gov.my
}

$(\mathrm{w} / \mathrm{w})$ of residual oil, metallic impurities and the organic compounds that can cause environmental problems and increase the land-fill disposal costs (Cheah and Siew, 2004). Due to these problems, many researchers had attempted to improve the effectiveness of bleaching earth as well as to extract the residual oil and regenerate the SBE (Boukerroui and Ouali, 2000; Tsai et al., 2002; Mahramanlioglu et al., 2010).

Other than being reused for the bleaching process, the regenerated SBE offers potential for application as an adsorbent in the treatment of palm oil mill effluent (POME). The average effluent production rate from a typical palm oil mill ranges from $65 \%$ to $70 \%$ of the fresh fruit bunches (FFB) processed. POME is an acidic, thick, brownish colloidal suspension containing $95 \%-96 \%$ of water, 
$0.6 \%-0.7 \%$ of oil and $4 \%-5 \%$ total solids including $2 \%-4 \%$ suspended solids (Ma, 1998). Recently, due to the increasing environmental quality awareness and the concerns on river water quality, the Department of Environment (DOE) has decided to impose more stringent discharge limits on the effluents discharged from the palm oil mills and other industries. Colour and biological oxygen demand (BOD) of wastewater are amongst the concerned parameters requiring compliance with the revised discharge limits. Wastewaters discharged to the water courses such as streams, rivers or the sea with a high level of colouration not only provide an undesirable appearance, but can also cause damage to the marine life. This is due to the possible deprivation of sunlight to the aquatic species living in the water. This study aims to evaluate the characteristics and adsorption capacity of the new bleaching earth (NBE), de-oiled spent bleaching earth (DSBE) and regenerated de-oiled SBE to decolourise as well as reduce the $B O D$ level of POME.

\section{MATERIALS AND METHODS}

\section{Materials}

NBE and SBE used in this study were obtained from a palm oil refinery. POME discharge was collected from a palm oil mill. The residual oil in the SBE was removed by a Soxhlet extraction method using hexane as the solvent. The DSBE was later regenerated by a combined acid and heat treatment. This acid-heat treated regenerated de-oiled spent bleaching earth is named RDSBE-AH. The acid treatment was carried out by impregnating the DSBE with $20 \mathrm{wt} \%$ of $\mathrm{H}_{2} \mathrm{SO}_{4}(1 \mathrm{M})$ and stirred for $5 \mathrm{hr}$ at $200 \mathrm{rpm}$. The clay was then washed with distilled water, dried in an oven followed by the heating of the clay in a furnace (Naberthem M-7/H) at $500^{\circ} \mathrm{C}$ for $2 \mathrm{hr}$.

\section{Adsorption Experiments}

The adsorption studies were performed by batch stirring technique where the clay was mixed and stirred at the studied conditions. The adsorption experiments were carried out by using $200 \mathrm{ml}$ of palm oil mill final effluent discharge treated with the different types of clays. The experiments were performed at various contact times ranging from 1 to $6 \mathrm{hr}$. The mixed solution was placed on the magnetic stirrer/heating mantle and stirred at 200 rpm for $4 \mathrm{hr}$. The clay dosage, temperature and $\mathrm{pH}$ were maintained at $5 \%, 40^{\circ} \mathrm{C}$ and $\mathrm{pH} 8$, respectively. Kinetic adsorption experiments were carried out to establish the effect of time on the adsorption process and to determine the rate of adsorption for components removal.
The influence of the dosage clay on the colour and BOD removal was performed by varying the dosage ratio between $5 \%$ and $25 \%$. The dosage ratio was calculated as the ratio of the weight of clay in the solution to the volume of the palm oil mill final effluent discharge. The contact time and $\mathrm{pH}$ for both tests on colour and BOD were maintained at $4 \mathrm{hr}$ and $\mathrm{pH} \mathrm{8,} \mathrm{respectively.} \mathrm{In} \mathrm{order} \mathrm{to} \mathrm{study} \mathrm{the}$ effect of $\mathrm{pH}$ on the adsorption, trials were carried out using various values of $\mathrm{pH}$ ranging from 2 to 10. Adjustment of $\mathrm{pH}$ was done by using standard alkali of $0.1 \mathrm{M} \mathrm{NaOH}$ and acid of $0.1 \mathrm{M} \mathrm{HCl}$. The clay dosage and contact time for studies on colour and BOD removal were kept constant at 5\% and 4 $\mathrm{hr}$, respectively.

The adsorption percentage $(R)$, was determined as the final removal percentage relative to the initial value of the component, calculated using the following equation:

$$
R=\frac{\left(C_{0}-C_{e}\right)}{C_{0}} \times 100 \% \quad \text { Equation }(1)
$$

where $R$ is the adsorption percentage of components $(\%), C_{o}$ is the initial value of components (mg litre ${ }^{-1}$ for BOD and Pt-Co for colour) and $C_{e}$ is the final value of components ( $\mathrm{mg}$ litre $^{-1}$ for BOD and Pt-Co for colour).

\section{Characterisation and Analysis}

The surface areas and pore volume of the samples were determined by nitrogen gas adsorption at $77 \mathrm{~K}$ by using a surface area analyser (Quantachrome Autosorb AS:Qwin Version 3.01, USA). The functional groups of different clay samples in the range $4000-650 \mathrm{~cm}^{-1}$ were carried out with a Fourier transform infra-red (FTIR) spectrometer (Frontier, Perkin Elmer, USA).

The treated palm oil mill final discharge was analysed for BOD and colour. The colour and BOD concentration were measured by a $\mathrm{HACH}$ DR 6000 (Germany) apparatus. All chemicals used in this study were analytical grade. All analysis were carried out in triplicate and the average values were taken.

\section{RESULTS AND DISCUSSION}

\section{Characterisation}

An adsorption process depends on the surface area, pore sizes distribution and surface chemistry of the adsorbents (Angin et al., 2013a). As shown in Table 1, the surface area of SBE was substantially reduced from $119.7 \mathrm{~m}^{2} \mathrm{~g}^{-2}$ of NBE to $19.4 \mathrm{~m}^{2} \mathrm{~g}^{-2}$ and the pore volume was also significantly reduced from 
$0.0552 \mathrm{~cm}^{3} \mathrm{~g}^{-1}$ of NBE to $0.0002 \mathrm{~cm}^{3} \mathrm{~g}^{-1}$. The reduction in surface area and pore volume of SBE indicates that the porous texture of the clay has been changed after being used in the oil refining process. The removal of residual oil from SBE with hexane as indicated by the adsorbent labelled DSBE slightly increased the surface area and pore volume. The surface area and pore volume of RDSBE-AH were found to be higher than NBE. The high increase in the surface area $\left(122.3 \mathrm{~m}^{2} \mathrm{~g}^{-1}\right)$ and pore volume $\left(0.0568 \mathrm{~cm}^{3} \mathrm{~g}^{-1}\right)$ of RDSBE-AH was possibly due to the acid reaction with the clay surface and the heating temperature which caused the dissolution of retained impurities, thus influencing the surface properties of the adsorbent. Similar effects were observed when clays were regenerated with sulphuric acid at high temperature by other researchers (Noyan et al., 2007; Sütcü and Demiral, 2009; Azargohar and Dalai, 2008; Sudaryanto et al., 2006). These results also indicate that the regeneration of the micropores would possibly have regenerated due to the removal of some of the retained substances.

TABLE 1. SURFACE AREA

\begin{tabular}{lcc}
\hline Sample & $\begin{array}{c}\text { Surface area } \\
\left(\mathbf{c m}^{\mathbf{2}} \mathbf{~}^{-\mathbf{}}\right)\end{array}$ & $\begin{array}{c}\text { Pore volume } \\
\left(\mathbf{c m}^{\mathbf{3}} \mathbf{g}^{-\mathbf{}}\right)\end{array}$ \\
\hline NBE & 119.7 & 0.0552 \\
SBE & 19.4 & 0.0002 \\
DSBE & 31.2 & 0.0139 \\
RDSBE-AH & 122.3 & 0.0568 \\
\hline
\end{tabular}

Note: NBE - new bleaching earth.

DSBE - de-oiled spent bleaching earth.

SBE - spent bleaching earth.

RDSBE-AH - acid-heat treatment regenerated de-oiled spent bleaching earth.
As shown in Figure 1, the patterns of the FTIR spectra of NBE, SBE, DSBE and RDSBE-AH are quite similar. All types of clays exhibited band in the FTIR spectra at $3350-3550 \mathrm{~cm}^{-1}$ which indicates the presence of stretching vibrations of $\mathrm{O}-\mathrm{H}$ of carboxylic acids. The presence of Si-O stretching was observed for all clays as indicated by the band near $980-1010 \mathrm{~cm}^{-1}$ (Meziti and Boukerroui, 2011). As compared to other clays, SBE exhibits additional bands at 2850 and $2930 \mathrm{~cm}^{-1}$ which indicates the presence of stretching vibration of $\mathrm{C}-\mathrm{H}$ of carbonaceous chains of oil and the free fatty acids. These bands correspond to the characteristic of residual oil. Another band at $1730 \mathrm{~cm}^{-1}$ was also observed for SBE indicating the presence of strong stretching vibration of ester carbonyl of residual oil. After residual oil was removed from SBE, these bands were no longer in existence as indicated in the spectrum of DSBE and RDSBE-AH which suggest that the de-oiling and regeneration processes had eliminated the oil residue adsorbed in the pores of SBE.

\section{Adsorption Study}

Effects of adsorbent. Figure 2 illustrates the visual observation on the colour changes from raw palm oil mill final effluent discharge to treated final effluent discharge when using different types of clays namely NBE, SBE, DSBE and RDSBE-AH. The colours of the final effluent discharge treated with NBE and RDSBE-AH were found to be higher than the colour of the final effluent discharge treated with SBE and DSBE. The colour that caused pollution is normally due to the presence of organic matter such as synthetic chemical dyes, algae species and

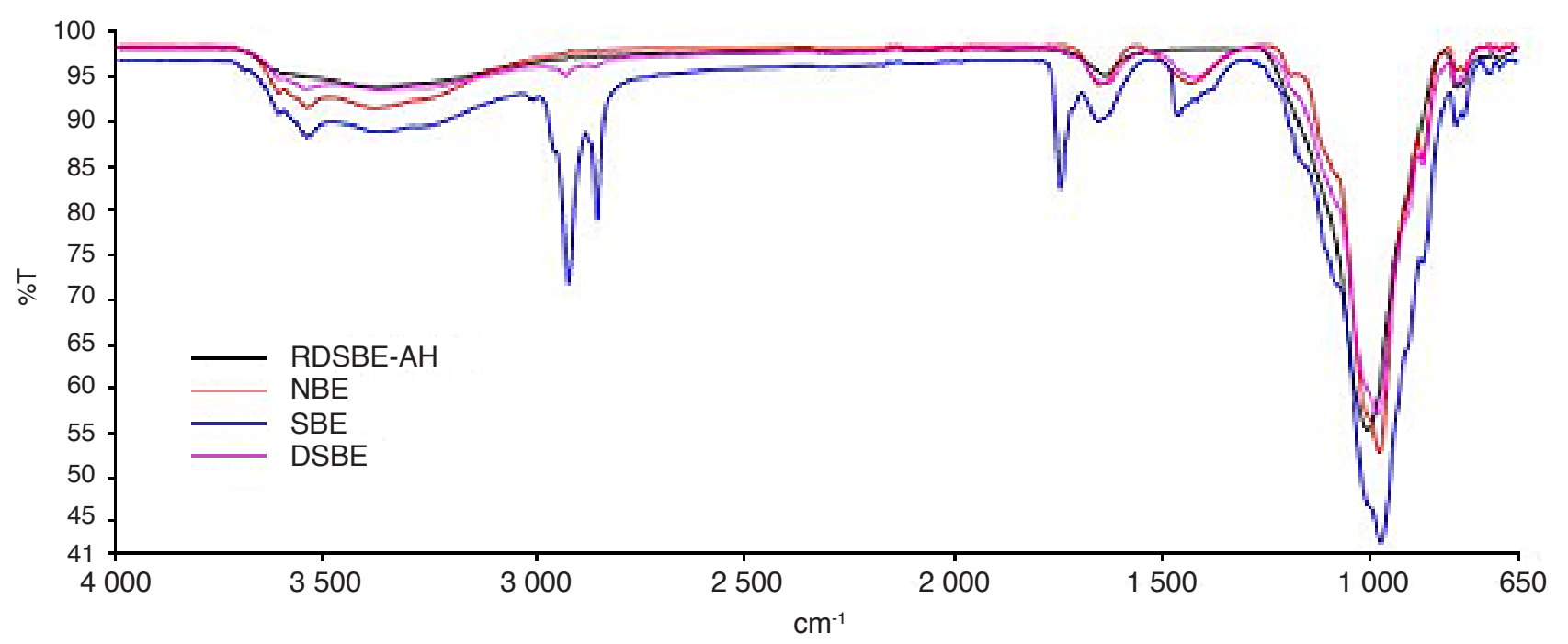

Note: RDSBE-AH - acid-heat treatment regenerated de-oiled spent bleaching earth.

NBE - new bleaching earth.

DSBE - de-oiled spent bleaching earth.

SBE - spent bleaching earth.

Figure 1. Fourier transform infra-red (FTIR). 

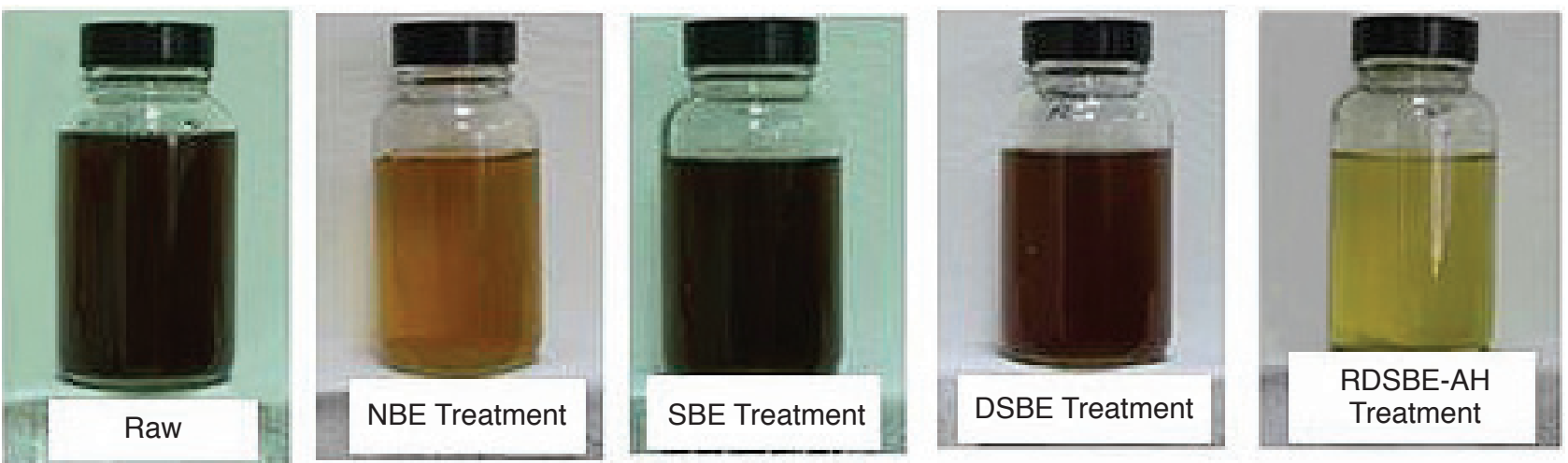

Figure 2. Colour effluent.

natural dissolve organics such as lignin and tannins (www.arviatechnology.com/applications). Table 2 shows a comparison of the amount of colour adsorbed by the four clays namely NBE, SBE, DSBE and RDSBE-AH. The decolourisation efficiency of RDSBE-AH is higher at $68.3 \%$ as compared to NBE at $51.0 \%$. SBE shows very low decolourisation efficiency as compared to the three clays. Differences in the adsorption efficiency were possibly due to the variation in properties of the clays such as surface area, pore volume and functional groups as presented in Table 1 and Figure 1. The highest to lowest order between the four clays for the amounts of colour being adsorbed were as follows; RDSBE$\mathrm{AH}(68.3 \%)>\operatorname{NBE}(51.0 \%)>\operatorname{DSBE}(24.9 \%)>\mathrm{SBE}$ $(18.8 \%)$. As RDSBE-AH possesses the largest specific surface area, it possibly resulted in the highest colour removal among the clays studied.

The percentages of BOD removal when using various types of clays (NBE, SBE, DSBE and RDSBE$\mathrm{AH})$ are presented in Table 2. The percentage BOD removal for RDSBE-AH was slightly lower than the NBE with values of $46.4 \%$ and $53.0 \%$, respectively. SBE exhibited the lowest value at $2.8 \%$ indicating possibly the surface of the clay was no longer active and the pores could possibly have been blocked by components. The slightly higher value of DSBE at $13.6 \%$ suggests that the residual oil that has been

TABLE 2. TYPES ADSORBENTS

\begin{tabular}{lcr}
\hline & \multicolumn{2}{c}{$\% \mathbf{R}$} \\
\cline { 2 - 3 } & Colour & BOD \\
\hline NBE & 51.0 & 53.0 \\
SBE & 18.8 & 2.8 \\
DSBE & 24.9 & 13.6 \\
RDSBE-AH & 68.3 & 46.4 \\
\hline
\end{tabular}

Note: NBE - new bleaching earth. DSBE - de-oiled spent bleaching earth. SBE - spent bleaching earth.

RDSBE-AH - acid-heat treatment regenerated

de-oiled spent bleaching earth.

$\mathrm{R}$ - adsorption percentage.

BOD - biological oxygen demand. removed from SBE provided more pores to open and was ready to adsorb certain amount of components. On comparing the amounts of BOD adsorbed among the four clays, the following order was found: NBE $(53.0 \%)>$ RDSBE-AH $(46.4 \%)>$ DSBE $(13.6 \%)>\operatorname{SBE}(2.8 \%)$. It had been noted by Mudoga et al. (2008) that textural and surface properties are related with the ability of an adsorbent to adsorb organic substances. As illustrated in Table 2, SBE and DSBE showed very poor performance in term of the decolourisation efficiency and BOD removal from the palm oil final effluent discharge. Thus, clays of NBE and RDSBE-AH were selected for conducting subsequent adsorption experiments.

Effect of clay dosage. Figure 3 presented the influence of clay dosage on colour when using NBE and RDSBE-AH. It was observed that at 5\% dosage of RDSBE-AH, the percentage colour removal was at $69.3 \%$ which was higher than NBE at 5\% dosage with reduction of $40.1 \%$. It was found that a gradual increase in the percentage of colour adsorption from $69.3 \%$ to $92.2 \%$ was achieved when the dosage of the RDSBE-AH was increased from $5 \%$ to $25 \%$, respectively. This result suggests that an increase of dosage would increase the amount of adsorbent particles which then led to a higher available sites binding for adsorption (Wang et al., 2010; Angin et al., 2013a). Noorimotlagh et al. (2014) reported a similar trend when conducting research on the use of activated carbon for the adsorption of a textile dye. The highest reduction in RDSBE-AH was observed after treatment with $25 \%$ dosage. It is clear therefore that a $25 \%$ RDSBE dosage produced the highest reduction in colour as compared with NBE when the same amount of clay was used. As for NBE, a $25 \%$ dosage resulted in a reduction in colour of $69.2 \%$.

The effect of clay dosage on the BOD of palm oil mill final effluent discharge is presented in Figure 4. It was observed that increasing the dosage of NBE from $5 \%$ to $25 \%$ gradually increased the percentage BOD removal from $33.0 \%$ to $41.3 \%$, respectively. RDSBE-AH also showed an increase 


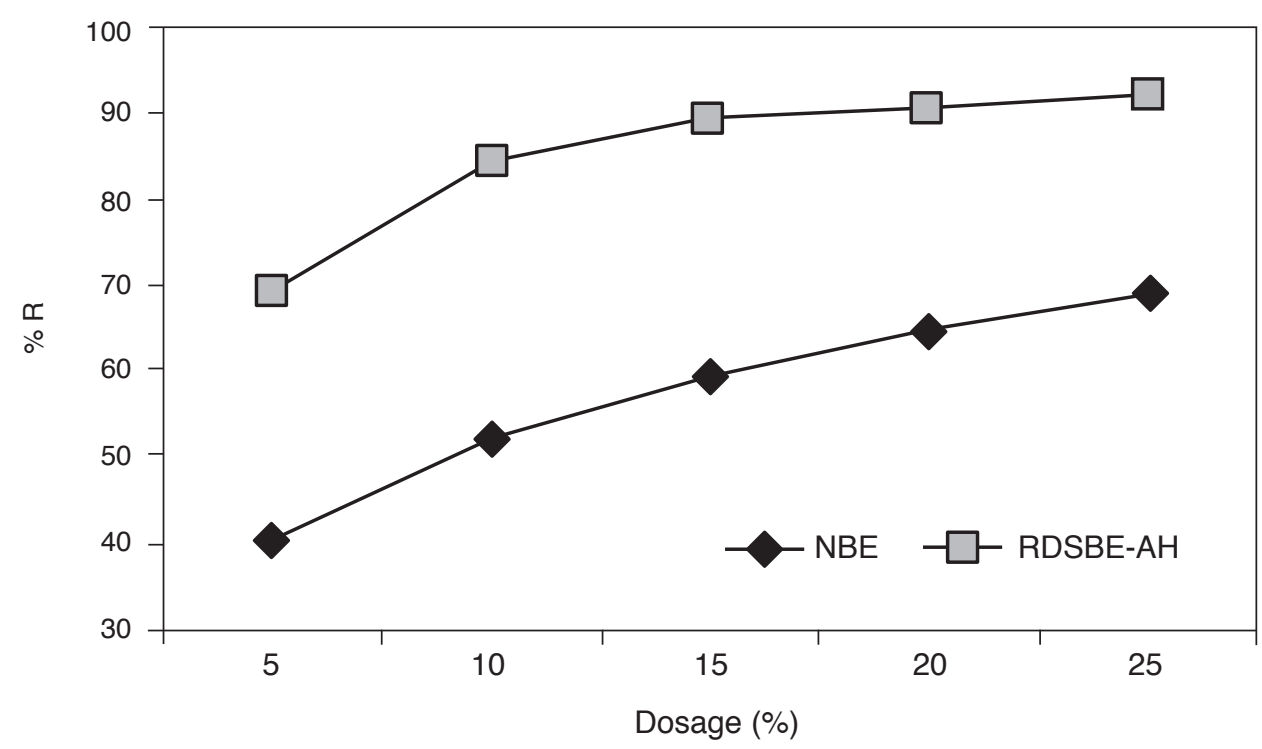

Note: NBE - new bleaching earth.

RDSBE-AH - acid-heat treatment regenerated de-oiled spent bleaching earth.

Figure 3. Effect dosage on colour.

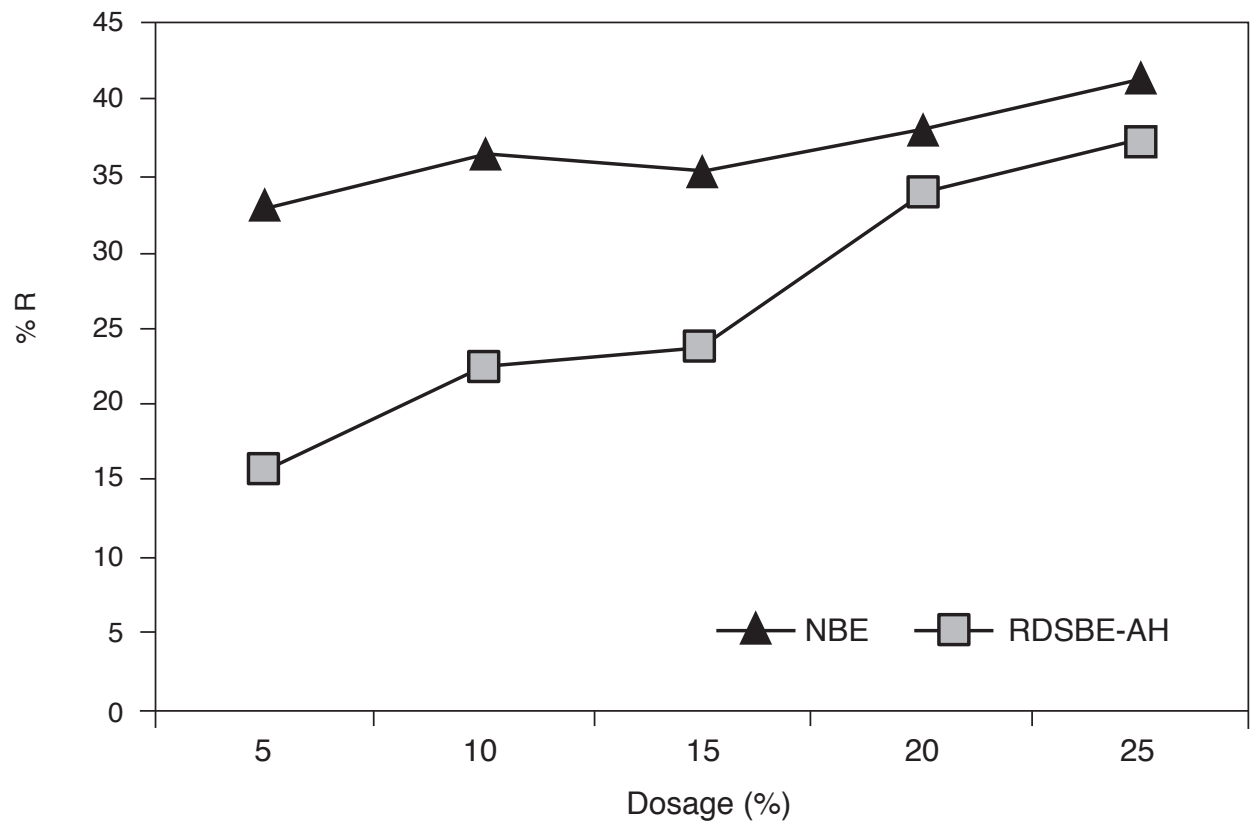

Note: NBE - new bleaching earth.

RDSBE-AH - acid-heat treatment regenerated de-oiled spent bleaching earth.

Figure 4. Effect dosage on biological oxygen demand (BOD).

of $\mathrm{BOD}$ percentage removal from $15.5 \%$ to $37.2 \%$ when the clay dosage was increased from 5\% to $25 \%$, respectively. Similar results for decolourisation and BOD removal where an increase in adsorbent dosage would lead to an increase in reduction are also observed by other researchers (Kheok and Lim, 1982; Nnadozie et al., 1989).

Effect of $\boldsymbol{p H}$. One of the important parameters influencing the adsorption of different target pollutants is the $\mathrm{pH}$ of the solution as it affects the surface properties and binding sites of adsorbents
(Lin et al., 2013). Figure 5 shows the variation in the colour adsorption of NBE and RDSBE-AH over a wide $\mathrm{pH}$ range from low acidic to high alkaline. It was observed that the colour removal in palm oil mill final effluent discharge treated with RDSBE decreased from $94.2 \%$ to $49.7 \%$ when the $\mathrm{pH}$ of the solution was raised from 2 to 10, respectively. Similar trend was observed for palm oil mill final effluent discharge treated with NBE where the percentage of colour reduction decreased from $53.4 \%$ to $22.5 \%$ when the $\mathrm{pH}$ was raised from 2 to 10 , respectively. Decolourisation seems to be effective 
when solution was at low $\mathrm{pH}$ value which was in the acidic condition. Results obtained from Figure 5 showed that RDSBE-AH was more effective in reducing the colour of palm oil mill final discharge than NBE. The differences in the properties of NBE and RDSBE-AH as indicated in Table 1 could have resulted in the different activity for reducing colour. The declining of solute adsorption with an increase in $\mathrm{pH}$ has also been observed by other researcher (Noorimotlagh et al., 2014).

In contrast, Figure 6 demonstrates an increase in BOD removal efficiency with the increase of $\mathrm{pH}$ in solution. Result for RDSBE-AH shows that the BOD percentage removal increased from $12.8 \%$ to $46.7 \%$ when the $\mathrm{pH}$ increased from 2 to 10, respectively. Similar behaviour was observed for NBE where increasing $\mathrm{pH}$ from 2 to 10 caused an increase in the BOD percentage removal from $28.6 \%$ to $41.3 \%$, respectively. These results suggest that the repulsion force between the solute molecules and adsorbent was strong which could probably lead to the low adsorption removal. Studies by other researchers had shown similar trend where the adsorption removal of methylene blue using activated carbon increased with an increase in $\mathrm{pH}$ (Ghaedi et al., 2014; Kunwar et al., 2003).

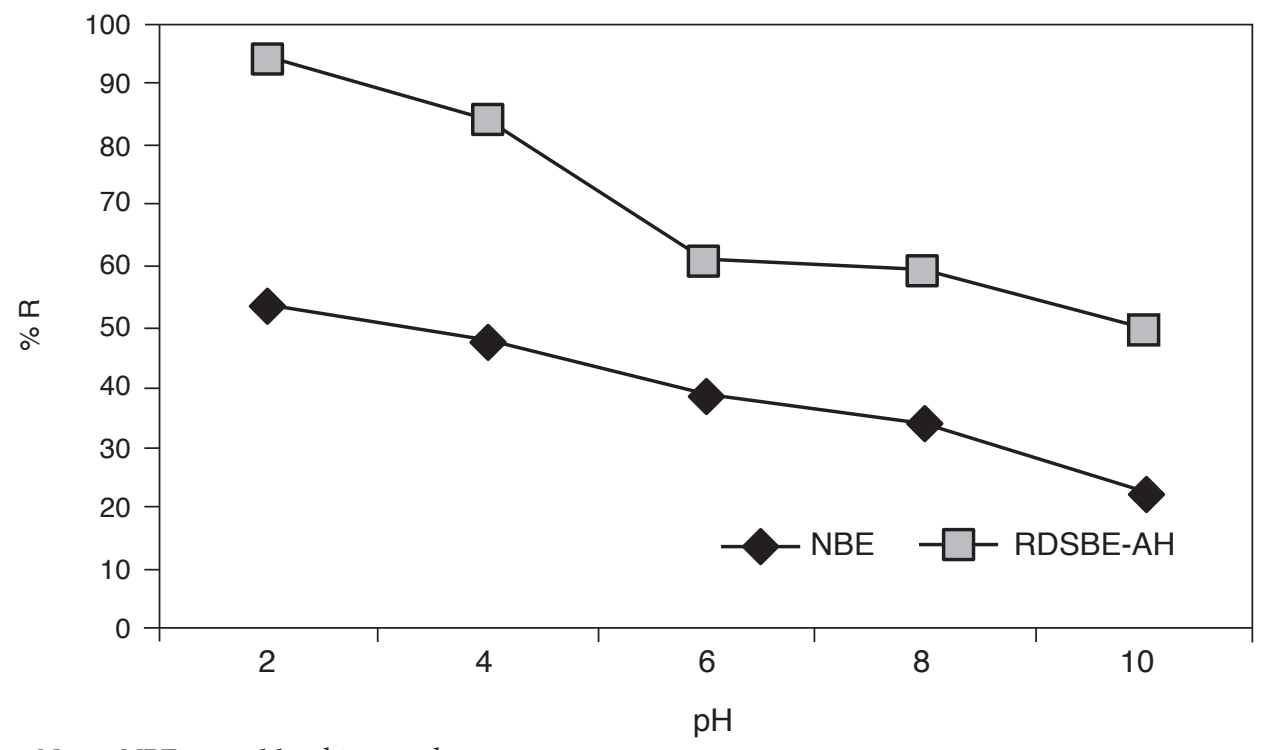

Note: NBE - new bleaching earth.

RDSBE-AH - acid-heat treatment regenerated de-oiled spent bleaching earth

Figure 5. Effect $\mathrm{pH}$ on colour.

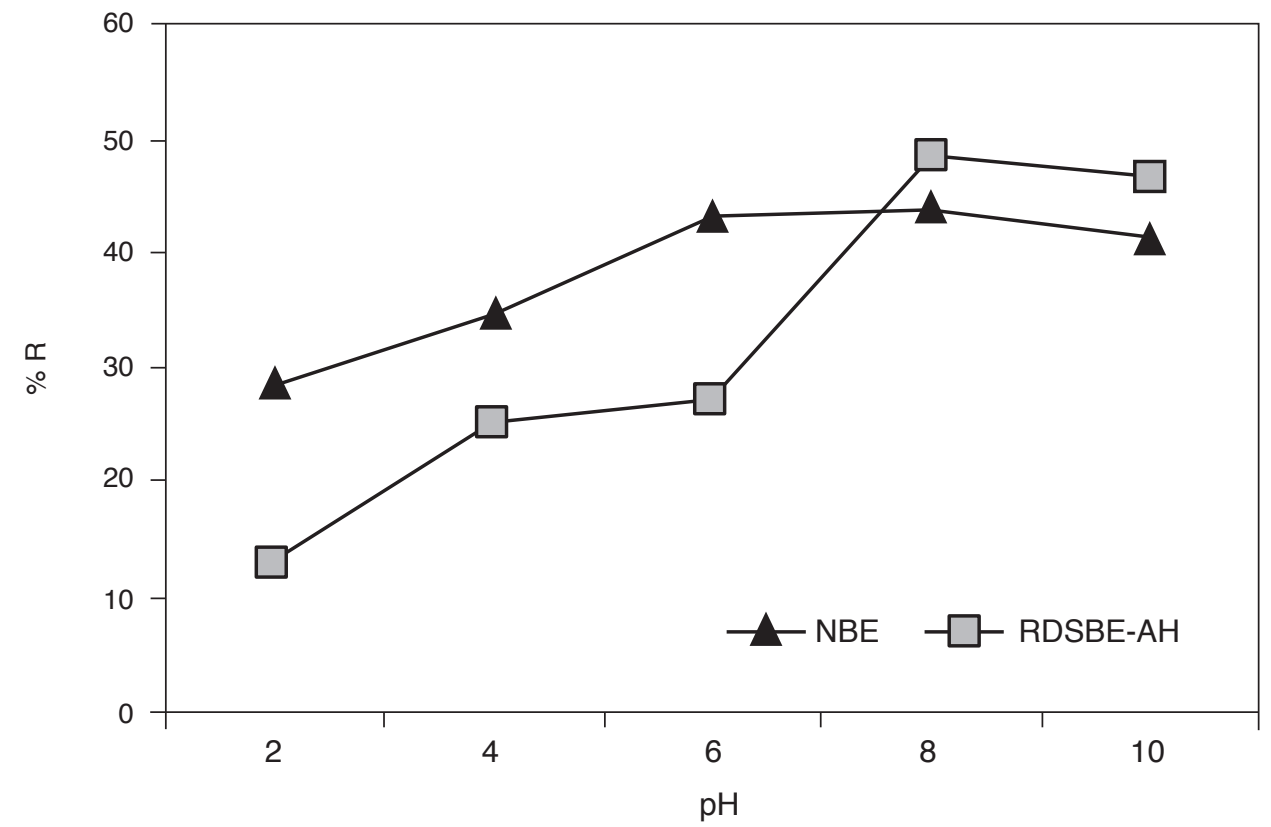

Note: NBE - new bleaching earth.

RDSBE-AH - acid-heat treatment regenerated de-oiled spent bleaching earth.

Figure 6. Effect $p H$ on biological oxygen demand (BOD). 
It was observed from Figures 5 and 6 that a different $\mathrm{pH}$ value for the same solution gave different effects on the removal of colour and BOD. The percentage colour reduction was reduced in between $61 \%$ and $59 \%$ at moderate $\mathrm{pH}$ values of around 6 to 8 treated with RDSBE-AH was used. At the same range of $\mathrm{pH}$ values (6 to 8) by using RDSBE-AH as the adsorbent, the BOD reduction was between $27 \%$ to $49 \%$. These results suggest that a pH close to 6 to 8 could be used for the adsorption process as it was reported that the normal $\mathrm{pH}$ range for irrigation is from 6.5 to 8.4 (www.fao.org/ docrep/t0551e03.htm). As for the operation at the field, from the results obtained, it is suggested to use only one $\mathrm{pH}$ value which is about 7 . With this $\mathrm{pH}$ value, both colour and BOD can be reduced quite effectively.

\section{Kinetic modeling}

Adsorption kinetic is one of the important aspects for pollutant removal process control. Kinetic models such as pseudo-first order and pseudo-second order model have been widely used to predict the mechanism involved in the adsorption process (Noorimotlagh et al., 2014). The Lagergren pseudo-first-order rate is given as the following equation (Ho, 2004):

$$
\log \left(q_{e}-q_{t}\right)=\log q_{e}-\left(\frac{k_{1}}{2.303}\right) t \quad \text { Equation (2) }
$$

where $q_{e}$ and $q_{t}$ are the amounts of adsorbed component at time $(t)$ and at equilibrium, respectively and $k_{1}\left(\mathrm{~min}^{-1}\right)$ is the first-order rate constant of the equation. The value of the rate constant $k_{1}$ can be obtained by the straight line of the plot $\log \left(q_{e}-q_{t}\right)$ versus $t$. It was found from the conducted experiments, the obtained coefficient determination value was very low, thus the firstorder kinetic model was not applicable. The pseudosecond order kinetic model was then applied to the experimental data which is expressed in the following equation (Ho, 2003):

$$
\frac{t}{q_{t}}=\left(\frac{1}{k_{2} q_{e}^{2}}\right)+\left(\frac{1}{q_{e}}\right) t
$$

Equation (3)

where $k_{2}$ (min.g $\mathrm{mg}^{-1}$ ) is the rate constant of the second-order equation, $q_{t}\left(\mathrm{mg} \mathrm{g}^{-1}\right)$ the amount of adsorption at time $t(\mathrm{~min})$, and $\mathrm{q}_{\mathrm{e}}$ is the amount of adsorption at equilibrium $\left(\mathrm{mg} \mathrm{g}^{-1}\right)$. The values of $q_{e}$ and rate constant $k_{2}$ and were calculated from intercept and slope of the plot of $t / q_{e}$, respectively.

Figure 7 presents the plot of $t / q$ versus time for the adsorption of colour on NBE and RDSBE-AH. The results obtained showed that the adsorption kinetics for both clays were well described by the pseudo-second order model with relatively high coefficient determination $\left(R^{2}\right)$ values. The $R^{2}$ values for NBE and RDSBE-AH were 0.9993 and 0.9992, respectively. Linear plot of $t / q$ versus time was also observed for the adsorption of BOD treated with NBE and RDSBE-AH as shown in Figure 8. It was found that both NBE and RDSBE-AH are well fitted with the pseudo-second order model and obtained high $R^{2}$ values of 0.9983 and 0.9609 , respectively. The linear regressions obtained from

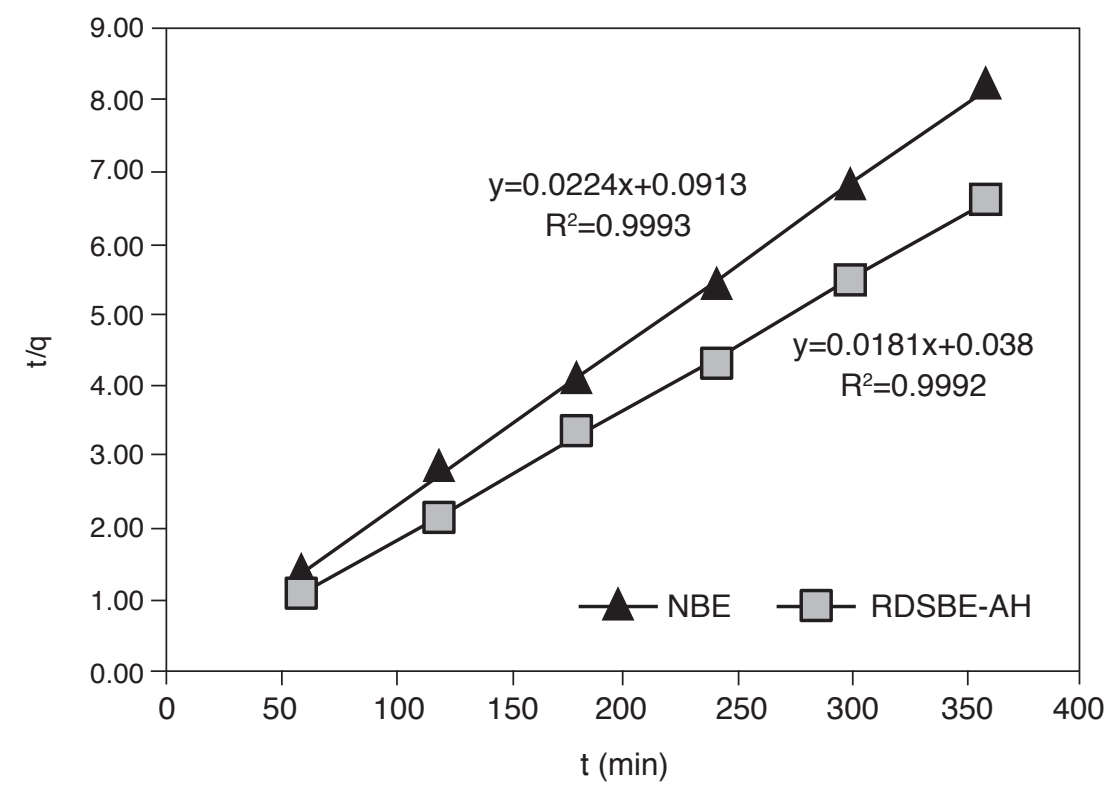

Note: NBE - new bleaching earth.

RDSBE-AH - acid-heat treatment regenerated de-oiled spent bleaching earth.

Figure 7. Pseudo-second order for colour. 


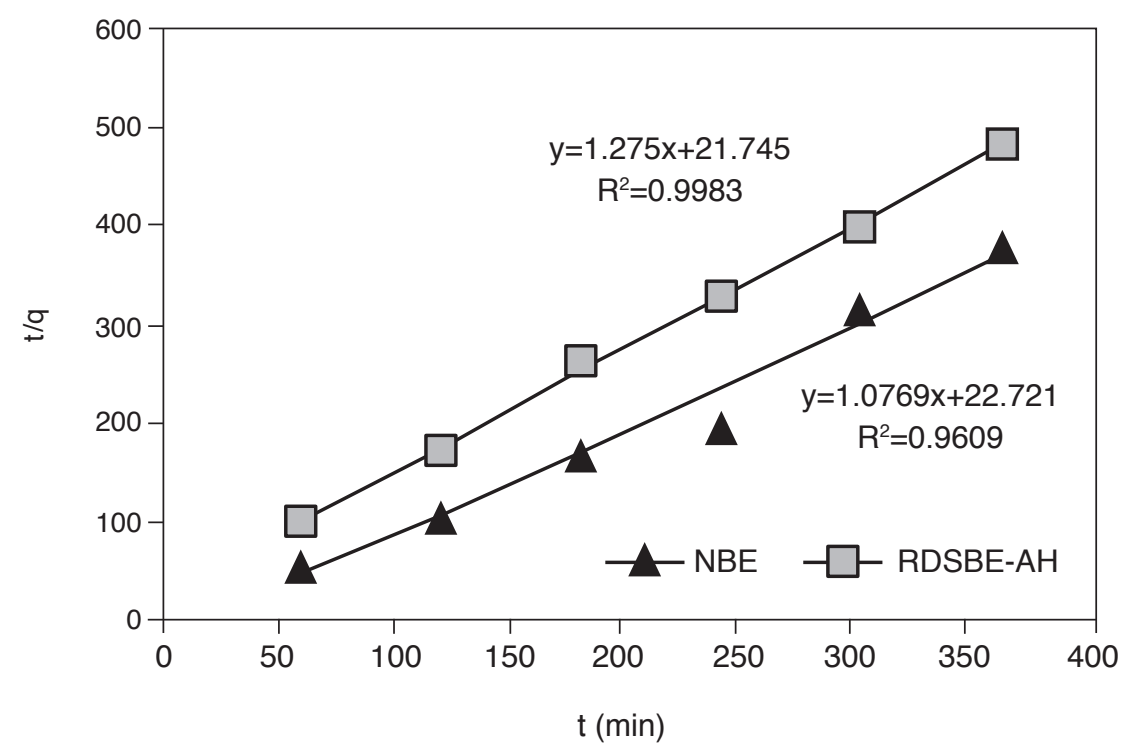

Note: NBE - new bleaching earth.

RDSBE-AH - acid-heat treatment regenerated de-oiled spent bleaching earth.

Figure 8. Pseudo-second order for biological oxygen demand (BOD).

Figures 7 and 8 suggest that the pseudo-second order model gives a good description of colour and BOD adsorption kinetics. The applicability of pseudo-second order model was observed by Umar et al. (2015) when they used coconut shell-based activated carbon for dye adsorption. Another kinetic study conducted by Angin et al. (2013b) also found that the adsorption process of dyestuff from aqueous solutions using activated carbon obtained from biochar obeyed the pseudosecond order model.

\section{CONCLUSION}

SBE regenerated by the impregnation with $\mathrm{H}_{2} \mathrm{SO}_{4}$ solution followed by a heat treatment exhibits a very promising performance in the decolourisation and BOD removal from palm oil mill final effluent discharge. This study has showed that the regeneration of SBE by acid and heat treatment has cleared the pore of the spent bleaching earth thereby increasing its surface area and pore volume, thus allowing more components/pollutants to be adsorbed. The kinetic results for both colour and BOD fit well with the pseudo-second order model with the coefficient determination values higher than 0.99 and 0.96, respectively. Comparing the adsorption efficiency showed that the regenerated SBE subjected to combined acid and heat treatments could perform better than the new bleaching earth, a finding that offers considerable opportunities to the millers as well as the refineries.

\section{ACKNOWLEDGEMENT}

The authors would like to extend their gratitude to the Director-General of MPOB for permission to publish this article.

\section{REFERENCES}

ANGIN, D; KÖSE, T E and SELENGIL, U (2013a). Production and characterization of activated carbon prepared from safflower seed cake biochar and its ability to absorb reactive dyestuff. Applied Surface Science, 280: 705-710.

ANGIN, D; ESRA, A and TIJEN, E K (2013b). Influence of process parameters on the surface and chemical properties of activated carbon obtained from biochar by chemical activation. Bioresource Technology, 148: 542-549.

AZARGOHAR, R and DALAI, A K (2008). Steam and $\mathrm{KOH}$ activation of biochar: experimental and modeling studies. Microporous and Mesoporous Materials, 110: 413-421.

BAYRAK, Y (2003). Adsorption isotherms in bleaching hazelnut oil. J. Amer. Oil. Chem. Soc., 80: 1143-1146.

BOUKERROUI, A and OUALI, M S (2000). Regeneration of a spent bleaching earth and its reuse in the refining of an edible oil. J. Chem. Technol. Biotechnol., 75: 773-776. 
CHEAH, K Y and SIEW, W L (2004). Regeneration of spent bleaching clay. MPOB Information Series No. 230

GHAEDI, $\mathrm{M}$; GOLESTANI NASAB, A; KHODADOUST, S; RAJABI, $M$ and AZIZIAN, S (2014). Application of activated carbon as adsorbents for efficient removal of methylene blue: kinetics and equilibrium study. J. Industrial and Engineering Chemistry, 20: 2317-2324.

HO, Y S (2004). Citation review of Lagergren kinetic rate equation on adsorption reaction. Scientometrics, 59(1): 171-177.

HO, Y S (2003). Removal of metal ions from sodium arsenate solution using tree fern. Trans IChemE, Part B 81: 352-356.

KHEOK, S and LIM, E (1982). Mechanism of palm oil bleaching by montmorillonite clay activated at various acid concentrations. J. Amer. Oil Chem. Soc., 59: 129-131.

KUNWAR, P S; DINESH, M; SARITA, S; TONDON, G $S$ and DEVLINA, G (2003). Color removal from wastewater using low-cost activated carbon derived from agricultural waste material. Ind. Eng. Chem. Res., 42: 1965-1976.

LIN L; ZHAI, S R; XIAO, ZY; SONG, Y; AN, Q D and SONG, X W (2013). Dye adsorption of mesoporous activated carbons produced from $\mathrm{NaOH}$-pretreated rice husks. Bioresource Technology, 136: 437-443.

MA, A N (1998). Environmental management for the palm oil industry. Paper presented at the Seminar Mesra Alam Kilang Sawit. 12 October 1998, Lahad Datu, Sabah.

MAHRAMANLIOGLU, M; OZGEN, O; CINARLI, A and KIZILCIKLI, I (2010). Adsorption of pyridine by acid treated spent bleaching earth. Asian J. Chem., 22 (2): 1428-1434.

MEZITI, C and BOUKERROUI, A (2011). Regeneration of a solid waste from an edible oil refinery. Ceramics International, 37: 1953-1957.

MUDOGA, H L; YUCEL, $\mathrm{H}$ and KINCAL, N S (2008). Decolorization of sugar syrups using commercial and sugar beet pulp based activated carbons. Bioresource Technology, 99: 3528-3533.
NNADOZIE, N; AROWOLO, T and AKPAN, H (1989). Quality of Nigerian palm oil after bleaching with local treated clays. J. Amer. Oil Chem. Soc., 66: 218-222.

NOORIMOTLAGH, Z; DARVISHI CHESHMEH SOLTANI, R; KHATAEE, A R; SHAHRIYAR, S and NOURMORADI, H (2014). Adsorption of a textile dye in aqueous phase using mesoporous activated carbon prepared from Iranian milk vetch. J. Taiwan Institute of Chemical Engineers, 45: 1783-1791.

NOYAN, H; USERREF, O and YUKSEL, S (2007). The effect of sulphuric acid activation on the crystallinity, surface area, porosity, and bleaching power of a bentonite. Food Chem., 105: 156-163.

SUDARYANTO, Y; HARTONO, S B; IRAWATY, W; HINDARSO, $\mathrm{H}$ and ISMADJI, $\mathrm{S}$ (2006). High surface area activated carbon prepared from cassava peel by chemical activation. Bioresource Technol., 97: 734-739.

SÜTCÜ, H and DEMIRAL, H (2009). Production of granular activated carbons from loquat stones by chemical activation. J. Analytical and Applied Pyrolysis, 84: 47-52.

TSAI, W T; CHEN, H P; HSIEH, M F; SUN, H F and CHIEN, S F (2002). Regeneration of spent bleaching earth by pyrolysis in a rotary furnace. J. Analytical and Applied Pyrolysis, 63: 157-170.

UMAR, I A; GIWA, A; SALISU, B; SALLAHUDEEN, $\mathrm{M}$ and MUSTAPHA, A (2015). Kinetics, equilibrium and thermodynamics studies of C.I. Reactive Blue 19 dye adsorption on coconut shell based activated carbon. International Biodeterioration \& Biodegradation, 102: 265-273.

WANG, L; ZHANG, J; ZHAO, R; LI, C; LI, Y and ZHANG, C (2010). Adsorption of basic dyes on activated carbon prepared from Polygonum orientale Linn: equilibrium, kinetic and thermodynamic studies. Desalination, 254: 68-74.

www.fao.org/docrep/t0551e03.htm. Wastewater characteristics and effluent quality parameters.

www.arviatechnology.com/applications. Wastewater colour removal. 